\title{
Protocolo de tratamento da sepse grave HUPE contra a sepse
}

\author{
Severe sepsis treatment protocol \\ HUPE against sepsis
}

\author{
Sérgio da Cunha* \\ Equipe multidisciplinar do HUPE de combate à sepse ${ }^{\dagger}$
}

\section{Resumo}

Em abril de 2012 o Ministério da Saúde brasileiro deu início ao projeto intitulado "Brasil contra a Sepse”. Em agosto do mesmo ano foi constituída a equipe multiprofissional para a condução do projeto no Hospital Universitário Pedro Ernesto (HUPE). Em setembro essa equipe iniciou a atualização de profissionais do staff do hospital, de residentes de medicina e enfermagem, e de alunos de graduação em medicina, visando a adesão ao protocolo de tratamento, que tem como objetivo a redução da mortalidade dos pacientes com sepse grave. O protocolo de tratamento consiste na execução do chamado pacote de seis horas da campanha de sobrevivência da sepse. Inclui: rápida identificação da sepse grave; coleta de exames laboratoriais, incluindo lactato arterial e hemoculturas, além de hemograma completo, glicose, ureia, creatinina, bilirrubina total, TAP e PTTa; iniciar antibioticoterapia na primeira hora após o diagnóstico; para os pacientes hipotensos com sinais de má-perfusão tecidual, incluindo lactato maior que $4 \mathrm{mmol} / \mathrm{l}$, expansão da volemia com reposição de solução salina a $0,9 \%, 30 \mathrm{ml} / \mathrm{kg}$ em 1 hora e avaliação da necessidade de aminas simpaticomiméticas, visando às seguintes metas hemodinâmicas: pressão venosa central entre 8 e $12 \mathrm{mmHg}$, pressão arterial média maior ou igual a $65 \mathrm{mmHg}$, saturação venosa central de oxigênio maior que $70 \%$, clareamento do lactato maior que $10 \%$ em seis horas e diurese maior que $0,5 \mathrm{ml} / \mathrm{kg} / \mathrm{h}$. Para que essas metas sejam atingidas foram providenciados: formulário de diagnóstico e conduta inicial do paciente com sepse grave; formulário de solicitação de bandeja com material para punção venosa profunda, medida de pressão venosa central e coleta de hemoculturas; fluxograma para a rápida obtenção 
da primeira dose de antibiótico; fluxograma para a rápida obtenção do resultado dos primeiros exames laboratoriais; agilização da liberação do resultado das culturas.

Descritores: Sepse; Mortalidade hospitalar; Sobrevida; Hemodinâmica; Protocolos clínicos.

\section{Abstract}

Brazilian National Health Institute initiated the project "Brazil against sepsis" in April 2012. In August of the same year a multiprofessional team was organized to take care of this project in Pedro Ernesto University Hospital. In September this team initiated medicine and nursing professionals, residents and graduation students training in order to obtain the best treatment protocol adhesion. The main objective of this protocol is the reduction of severe sepsis mortality. The treatment protocol is based on the Surviving Sepsis Campaign six hour package. It includes: quick severe sepsis recognition; laboratory exams collection, including arterial lactate and blood cultures, and also hemogram, glucose, urea, creatinine, total bilirubin, prothrombin time (INR) and partially activated thromboplastin time; antibiotic therapy initiated within the first hour of diagnosis; for patients with hypotension, with signs of inadequate tissue perfusion, including arterial lactate $>4 \mathrm{mmol} / \mathrm{l}$, blood volume expansion with $0,9 \%$ saline, 20 to $30 \mathrm{ml} / \mathrm{kg}$ in the first hour, and evaluation of vasopressor amines indication. The hemodynamic targets are: central venous pressure -8 to $12 \mathrm{mmHg}$; mean arterial pressure $>65 \mathrm{mmHg}$; central venous oxygen saturation $>70 \%$; lactate clearance $>10 \%$ in 6 hours; diuresis $>0,5 \mathrm{~mL} /$ $\mathrm{kg} / \mathrm{h}$. In order to achieve these goals some arrangements were provided: form of diagnosis and initial management of patients with severe sepsis; request form to obtain tray with material for deep venous puncture, central venous pressure measurement and blood cultures bottles; flowchart for quickly obtaining the first dose of antibiotic, flowchart for rapid achievement of the first laboratory tests; expediting the release of the results of cultures.
Keywords: Sepsis; Mortality; Survivorship (public health); Hemodynamics; Clinical Protocols.

\section{Introdução}

Os conceitos de sepse, sepse grave e choque séptico foram estabelecidos em conferência de consenso realizada há 20 anos. ${ }^{1}$ Ficou definida como síndrome de resposta inflamatória sistêmica a presença de dois ou mais dos quatro seguintes parâmetros: temperatura maior que $38^{\circ} \mathrm{C}$ ou menor que $36^{\circ} \mathrm{C}$; frequência cardíaca maior que $90 \mathrm{bpm}$; frequência respiratória maior que $20 \mathrm{rpm}$ ou pressão parcial de gás carbônico $\left(\mathrm{PaCO}_{2}\right)$ menor que $32 \mathrm{mmHg}$; leucometria maior que $12.000 / \mathrm{mm}^{3}$ ou menor que $4.000 /$ $\mathrm{mm}^{3}$ ou maior que $10 \%$ de formas imaturas. Essa síndrome pode ser desencadeada por várias condições clínicas, tais como: pancreatite aguda, politraumatismo, transfusões múltiplas de hemoderivados, isquemia tecidual. Ficou definida como sepse a síndrome de resposta inflamatória sistêmica desencadeada por infecção. Definiu-se como sepse grave aquela em que há sinais de hipoperfusão (alteração do nível de consciência, oligúria, aumento do lactato sanguíneo), hipotensão, ou disfunção orgânica.

Nas últimas décadas tem sido observado o aumento do número de casos de sepse. ${ }^{2}$ Isto tem sido resultado de vários fatores, entre eles: 1) maior longevidade da população mundial, face ao melhor controle de doenças crônicas (o comprometimento do sistema imune do idoso o torna vulnerável às infecções graves); 2) realização de maior número de procedimentos invasivos, que rompem barreiras de defesa do organismo contra a invasão microbiana; 3) realização de cirurgias mais complexas, especialmente casos de câncer antes considerados inoperáveis e que agora têm proposta de tratamento cirúrgico; 4) síndrome de imunodeficiência adquirida, associada ao desenvolvimento de inúmeras infecções por micro-organismos oportunistas, em ambiente de carência imunológica; 5) uso crescente de imunossupressores e corticosteroides.

A despeito do grande avanço da medicina nas últimas décadas, não há redução significativa da letalidade da sepse. Esse fato motivou a criação de campanha voltada ao aumento da 
sobrevivência na sepse. Um grande grupo de reconhecidos estudiosos do tema elaborou uma proposta terapêutica baseada nos estudos mais recentes que haviam demonstrado benefícios na evolução desses pacientes. A chamada Surviving sepsis campaign teve seu primeiro texto publicado em 2004, ${ }^{3}$ revisado em $2008,{ }^{4}$ e recentemente atualizado. $^{5}$

Quatro estudos se destacam na avaliação da epidemiologia da sepse no Brasil. O estudo BASES $^{6}$ envolveu 1.383 pacientes de unidades de terapia intensiva de cinco centros brasileiros. Observou letalidade de $46,9 \%$ nos pacientes com diagnóstico de sepse grave e de 52,2\% naqueles com choque séptico. O estudo SEPSE BRASIL, ${ }^{7}$ que também avaliou apenas pacientes internados em unidades intensivas, envolveu 521 pacientes de 75 centros, observando letalidade de $34,4 \%$ na sepse grave e $65,3 \%$ no choque séptico. O estudo $\operatorname{COSTS}^{8}$ foi desenhado para avaliação do custo da assistência ao paciente séptico, observando custo significativamente superior dos pacientes não sobreviventes. Nesse estudo observou-se também maior letalidade dos pacientes internados em instituições públicas. $\mathrm{O}$ estudo PROGRESS 9 envolveu 12.881 pacientes de 276 centros de 37 países. O Brasil contribuiu com 969 pacientes de oito centros. A letalidade da sepse grave observada aqui foi de $67,4 \%$ e ficou situada entre as maiores do mundo.

Em abril de 2012 o Ministério da Saúde brasileiro deu início ao projeto intitulado "Brasil contra a Sepse". Em agosto do mesmo ano foi constituída uma equipe multiprofissional para a condução do projeto no Hospital Universitário Pedro Ernesto (HUPE). Em setembro essa equipe iniciou a atualização de profissionais do staff do hospital, de residentes de medicina e enfermagem e de alunos de graduação em medicina, visando adesão ao protocolo de tratamento, que tem como objetivo a redução da letalidade da sepse grave.

\section{Protocolo de tratamento da}

\section{sepse grave}

Paciente-alvo: paciente adulto (idade $>18$ anos) com sepse grave.
Local de aplicação do protocolo: todas as unidades do hospital.

1. Identificação precoce de sepse grave baseada em:

a. presença ou presunção de infecção associada a dois dos sinais de síndrome de resposta inflamatória sistêmica: temperatura maior que $38^{\circ} \mathrm{C}$ ou menor que $36^{\circ} \mathrm{C}$; frequência respiratória (FR) maior que $20 \mathrm{rpm}$ ou $\mathrm{PaCO}_{2}$ menor que $32 \mathrm{mmHg}$; FC maior que $90 \mathrm{bpm}$; leucometria maior que 12.000 ou menor que $4.000 / \mathrm{mm}^{3}$, ou mais de $10 \%$ de formas jovens;

b. presença de pelo menos uma das disfunções orgânicas abaixo conceituadas:

i. cardiovascular: hipotensão arterial (pressão sistólica $<90 \mathrm{mmHg}$ ou pressão arterial média $<70 \mathrm{mmHg}$ );

ii. respiratória: lesão pulmonar aguda levando à hipoxemia $\left(\mathrm{PaO}_{2} / \mathrm{FiO}_{2}<\right.$ 300);

iii. renal (oligúria e/ou creatinina elevada): diurese menor que $0,5 \mathrm{ml} /$ $\mathrm{kg} / \mathrm{h}$ por pelo menos duas horas, mesmo após ressuscitação volêmica, ou creatinina maior que $2 \mathrm{mg} / \mathrm{dl}$;

iv. hepática (hiperbilirrubinemia direta): bilirrubina total maior que 2 $\mathrm{mg} / \mathrm{dl}$ ou INR maior que 1,5 ou TTPa maior que $60 \mathrm{~s}$;

v. hematológica: plaquetopenia menor que $100.000 / \mathrm{mm}^{3}$ ou queda de $50 \%$ ou mais nas últimas 72 horas;

vi. SNC (encefalopatia, alteração do estado mental): agitação psicomotora, confusão mental, rebaixamento do nível de consciência, delirium;

vii. metabólica: $\mathrm{pH}$ menor que 7,30 ou excesso de base menor que $5 \mathrm{mEq} / \mathrm{l}$ com lactato maior que $1,5 \mathrm{vez}$ o normal. 


\section{Abordagem diagnóstica e terapêutica}

a. Colher hemoculturas antes do início da terapia antimicrobiana: 2 amostras de hemocultura colhidas sem intervalo entre as coletas e de sítios diferentes. Colher volume de sangue equivalente a $10 \%$ do volume total do frasco. Manter o frasco em temperatura ambiente e encaminhar prontamente à bacteriologia . A solicitação da cultura deve conter a informação "Protocolo de sepse grave".

b. Técnica de coleta de hemocultura (Coordenadoria de Controle e Infecção Hospitalar - CCIH/HUPE/UERJ):

i. Identificar corretamente o frasco com os seguintes dados: data, número da amostra, hora da coleta, registro, nome do paciente e leito;

ii. Higienizar as mãos;

iii. Identificar a veia, preferindo os locais com menor colonização da pele (dorso das mãos e prega ulnar);

iv. Calçar as luvas de procedimento;

v. Fazer a desinfecção da tampa do frasco de hemocultura com álcool 70\%;

vi. Proceder à limpeza da pele com solução detergente (sabão), retirando o excesso com gaze seca;

vii. Realizar a antissepsia local com solução alcoólica de clorexidina $0,5 \%$ ( $1^{\mathrm{a}}$ opção) ou povidine alcoólico ( $2^{\mathrm{a}}$ opção) ou álcool 70\% com 3 friç̧ões ( $3^{\text {a }}$ opção), a partir do ponto selecionado, com movimentos circulares de dentro para fora, aguardando a secagem por 1 minuto. Usar sempre produtos da mesma linha para degermação e antissepsia: PVPI degermante/PVPI alcoólico, ou clorexidina degermante/clorexidina alcoólica; viii. Realizar a punção lentamente sem tocar o local onde foi realizada a antissepsia;

ix. Não se recomenda a troca de agulha para inocular o sangue no frasco, pois essa prática aumenta a incidência de acidente perfurocortante;

x. Material utilizado: touca, máscara, luvas de procedimento, bandeja, frasco de hemocultura, agulha e seringa estéril.

c. Colher culturas de outros sítios potencialmente envolvidos no quadro séptico do paciente. A solicitação da cultura deve conter a informação "Protocolo de sepse grave".

d. Iniciar a terapia antimicrobiana na primeira hora de instalação da sepse grave. A coleta de culturas não deve retardar demasiadamente o início da terapia antimicrobiana. Para agilizar a obtenção da primeira dose do antibiótico o mesmo deve ser solicitado em receituário comum (em 2 vias) contendo: nome do paciente, matrícula (é dispensável), enfermaria e leito, nome do medicamento, dose, hora do pedido, carimbo e assinatura do médico, e a informação "Protocolo de sepse grave". Um membro da equipe de saúde deve se dirigir à farmácia onde ocorrerá a imediata liberação do medicamento, a partir de estoque exclusivo para essa finalidade. Será atestada, nas duas vias do receituário, a hora exata de dispensação do medicamento pela farmácia. Uma das vias será arquivada e a outra voltará para a enfermaria. As demais doses do antibiótico serão disponibilizadas após o lançamento na prescrição on-line e preenchimento do formulário da CCIH, como é preconizada a liberação de antibióticos. 
e. Utilizar antibióticos por via intravenosa, preferencialmente bactericidas. Nos pacientes com disfunção renal, utilizar dose plena dos antimicrobianos nas primeiras 24 horas. Seguir orientação do Guia de antimicrobianos para terapia empírica, elaborado pela $\mathrm{CCIH}$ do HUPE. Se indicado, baseado no resultado das culturas, descalonar o esquema antimicrobiano.

f. Exames mínimos adicionais: gasometria arterial com lactato sérico, hemograma completo, glicose, ureia, creatinina, bilirrubinas, INR, TTPa. A solicitação desses exames pode ser resumida pela informação "Protocolo de sepse grave”. Esta informação agilizará a liberação do resultado. $\mathrm{O}$ resultado da gasometria arterial com lactato deve ser obtido rapidamente (ideal < 30 minutos). Em caso de valores elevados de lactato, ele deve ser repetido a cada duas horas, tendo como meta clareamento de lactato [(lactato inicial - lactato final/lactato inicial) x 100] maior que $10 \%$, nas primeiras 6 horas de assistência.

g. Abordagem hemodinâmica: a reposição volêmica inicial deve ser precoce e agressiva. Pacientes hipotensos ou com hiperlactatemia (valores de lactato superiores à normalidade) devem receber reposição volêmica inicial de $30 \mathrm{ml} /$ $\mathrm{kg}$ de peso nos primeiros 60 minutos de assistência, sob a forma de soluções cristaloides: solução salina $0,9 \%$ ou ringer lactato. Aqueles que apresentarem hipotensão refratária à reposição inicial de fluidos ou hiperlactatemia com valores de lactato maior que duas vezes o valor da normalidade (> $4 \mathrm{mmol} / \mathrm{l}$ ) devem ser submetidos à ressuscitação guiada por metas. Para tanto, puncionar acesso venoso profundo que permita medidas de pressão venosa central (PVC) e saturação venosa central de
$\mathrm{O}_{2}\left(\mathrm{SvcO}_{2}\right)$. Manter a reposição rápida de volume visando PVC entre 8 e 12 $\mathrm{mmHg}\left(\sim 11\right.$ a $\left.16 \mathrm{cmH}_{2} \mathrm{O}\right)$ em pacientes fora da ventilação mecânica (VM), e 12 a $15 \mathrm{mmHg}\left(\sim 16\right.$ a $\left.20 \mathrm{cmH}_{2} \mathrm{O}\right)$ naqueles em VM. Uma vez tendo atingido a PVC programada, verificar se já se obteve PAM > $65 \mathrm{mmHg}$. Caso contrário, iniciar ou aumentar a dose da noradrenalina, até atingir essa meta. Uma vez atingida, verificar $\mathrm{SvcO}_{2}$ : se menor que $70 \%$ verificar hematócrito; se menor que $30 \%$ transfundir concentrado de hemácia. Se hematócrito maior que $30 \%$ e $\mathrm{SvcO}_{2}$ menor que $70 \%$, iniciar dobutamina até dose máxima de 20 microgramas $/ \mathrm{kg} /$ minuto. Metas finais: PVC: 8 a $12 \mathrm{mmHg}$ (ou 12 a 15 $\mathrm{cmH}_{2} \mathrm{O}$ ); PAM maior que $65 \mathrm{mmHg}$; $\mathrm{SvcO} 2$ maior que $70 \%$; débito urinário maior que $0,5 \mathrm{ml} / \mathrm{kg} / \mathrm{h}$; clareamento de lactato maior que $10 \%$ nas primeiras seis horas.

\section{Outras medidas relevantes}

a. Caso o paciente tenha choque séptico refratário à reposição hídrica e aos vasopressores iniciar hidrocortisona 200 a 300 mg/dia em infusão venosa contínua. Vinte e quatro horas após a suspensão da amina vasopressora o corticoide deve ter sua dose reduzida à metade a cada 3 dias, sendo descontinuado após 3 dias da dose de $50 \mathrm{mg} /$ dia $(200-100-50-0)$.

b. Caso o paciente esteja em ventilação mecânica, todos os esforços devem ser feitos para manter a pressão de platô menor que $30 \mathrm{cmH}_{2} \mathrm{O}$ e o volume corrente menor que $6 \mathrm{ml} / \mathrm{kg}$ de peso.

c. Manter controle glicêmico, objetivando glicemias abaixo de $180 \mathrm{mg} / \mathrm{dl}$. Evitar hipoglicemias. Seguir protocolo específico. 


\section{Referências}

1. Bone RC, Balk RA, Cerra FB, Dellinger RP, Fein AM, Knaus WA, et al. Definitions for sepsis and organ failure and guidelines for the use of innovative therapies in sepsis. The ACCP/SCCM Consensus Conference Committee. American College of Chest Physicians/Society of Critical Care Medicine. Chest. 1992;101(6):1644-55.

2. Martin GS, Mannino DM, Eaton S, Moss M. The epidemiology of sepsis in the United States from 1979 through 2000. N Engl J Med. 2003 Apr 17;348(16):1546-54.

3. Dellinger RP, Carlet JM, Masur H, Gerlach H, Calandra T, Cohen J, et al. Surviving Sepsis Campaign Guidelines for Management of Severe Sepsis and Septic Shock. Crit Care Med. 2004;32(3):858-73.

4. Dellinger RP, Levy MM, Carlet JM, Bion J, Parker MM, Jaeschke R, et al. Surviving Sepsis Campaign: International Guidelines for Management of Severe Sepsis and Septic Shock: 2008. Crit Care Med. 2008;36(1):296-327.

5. Dellinger RP, Levy MM, Rhodes A, Annane D, Gerlach H, Opal SM, et al.
Surving Sepsis Campaign: International Guidelines for Management of Severe Sepsis and Septic Shock: 2012. Crit Care Med. 2013;41(2):580-637. http://dx.doi.org/10.1097/ CCM.0b013e31827e83af.

6. Silva E, Pedro MA, Sogayar ACB, Mohovic T, Silva CL, Janiszewski M, et al. Brazilian Sepsis Epidemiological Study (BASES study). Crit Care. 2004;8(4):R251-60.

7. Sales Jr JA, David CM, Hatum R, et al. Sepse Brasil: Estudo Epidemiológico da Sepse em Unidades de Terapia Intensiva Brasileiras*. Rev Bras Ter Intensiva. 2006;18 (1):9-17.

8. Sogayar AMC, Machado FR, Rea-Neto A, Dornas A, Grion CM, Lobo SM, et al. A multicentre, prospective study to evaluate costs of septic patients in Brazilian intensive care units. Pharmaco Economics. 2008;26(5):425-34.

9. Beale R, Reinhart K, Brunkhorst FM, Dobb G, Levy M, Martin G, et al. Promoting Global Research Excellence in Severe Sepsis (PROGRESS): lessons from an international sepsis registry. Infection. 2009 Jun;37(3):22232. http://dx.doi.org/10.1007/s15010-0088203-z.

\section{${ }^{\dagger}$ Equipe multidisciplinar do HUPE de combate à sepse:}

Eliane P. P. Assumpção

Elisabete N. Ferreira

Jorge da S. Motta

Rogério M. de Souza

Haroldo C. da Silva

William O. da Silva

Paulo V. Damasco

Mário C. A. Perez

Pedro G. Coscarelli

Jorge Eduardo da S. S. Pinto

Aloysio G. da Fonseca

Maria Cristina A. Maya
Luciana G. Assad

Luana F. de Almeida

Fernanda R. Rodrigues

Ronaldo R. Sampaio

Jaqueline do A. Santos

Augusto César C. Ferreira

Viviane S. e Silva

Elizabeth de A. Marques

Vagner I. Lobão

Irene de S. e Silva

Ana Alice de A. Triani 